\title{
Estimating RUSLE C-Factor Values for Great Barrier Reef Catchments using Satellite Derived Ground Cover Estimates
}

\author{
$\underline{\text { Rebecca Trevithick }}^{\mathrm{a}}$ and Peter Scarth ${ }^{\mathrm{a}}$ \\ ${ }^{a}$ Remote Sensing Centre, Ecosciences Precinct, 41 Boggo Road, Dutton Park 4102, Australia. \\ Email: rebecca.trevithick@science.dsitia.qld.gov.au
}

\begin{abstract}
Ground cover is a primary contributing factor in preventing hillslope erosion. Accurate modelling of this erosion is therefore dependent on accurate estimates of ground cover. Ground cover is temporally and spatially variable and, as such, remote sensing is an ideal source of ground cover estimates over large geographic areas. For the Great Barrier Reef, this information has generally been derived from the Remote Sensing Centre (RSC) (within the Queensland Department of Science, Information Technology, Innovation and the Arts) Bare Ground Index/Ground Cover Index (BGI/GCI). The BGI/GCI has been readily adopted by the modelling community as a preferred source of ground cover information at both the paddock and catchment scale.

While the BGI/GCI has been well received by the modelling community, it has been reported to overestimate ground cover by various authors, when compared with visual assessments. The BGI/GCI is calibrated and validated against point intercept ground cover data. Visual assessments of ground cover have been shown to estimate less ground cover, particularly in the middle ranges, when compared with point intercept/BGI/GCI estimates. In general point intercept methods are regarded as more reliable than visual estimates. Typically, modelling frameworks utilise ground cover data using the RUSLE model. In Australia the RUSLE C-factor is typically determined using as: from visual assessments, it is reasonable to expect an underestimate of the RUSLE C-factor when using satellite based estimates. Therefore, to obtain accurate C-factor estimates from satellite data, it may be necessary to adjust for the source of the ground cover data. In addition, the BGI/GCI has recently been replaced by the Fractional Cover Index (fCI). It is not known what the effect the fCI will have on ground cover estimates. This paper looks to investigate both the performance of the new fCI product on ground cover and $\mathrm{C}$-factor estimates and explore the possibility of adjusting $\mathrm{C}$-factor estimates to account for source data that is obtained from satellite, rather than visual field estimates.
\end{abstract}

Two long-term average dry-season bare ground indexes were compared (BGI/GCI and fCI). Both products were identically masked for cloud, cloud shadow, water and foliage projective cover (FPC) greater than 15\%. Total ground cover rasters for each catchment were calculated by taking the inverse of the bare fraction for each raster and were clipped to catchment boundaries. Difference rasters for both total ground cover and derived C-factors were calculated. Additionally, satellite ground cover estimates were adjusted to an equivalent visual estimate by a non-linear conversion function. The adjusted visual estimates were then converted into $\mathrm{C}$-factors (adjusted-fCI). The density distributions and medians for total ground cover, Cfactors and adjusted $\mathrm{C}$-factors for both indexes were also calculated. There was very little predicted difference in erosion predictions between the new fCI product and the BGI/GCI. A slightly lower median ground cover value for the fCI did not translate into any appreciable difference in the RUSLE C-factor. The median C-factors for both indexes were typically low for all catchments. The lack of change in the C-factor is attributed to the high levels of ground cover predicted for both indexes, for all catchments. Changes at high levels of ground cover have minimal effect with the Rosewell conversion function. In comparison, the distribution of differences between the BGI/GCI and the adjusted-fCI, shows considerable areas of very high decreases in ground cover and large increases in C-factors. For example, the effect of this adjustment in the Fitzroy was to reduce median ground cover from $75 \%$ (BGI/GCI) to $52 \%$ (adjusted-fCI) and increase the median $\mathrm{C}$-factor from 0.01 to 0.05 . The spatial distribution of these increases also varies, which in itself would affect modelling outcomes. All C-factor estimates were reasonable for rangelands.

The conversion function between satellite and visual estimates relies on an accurate determination of the relationship between visual and objective estimates and there is limited research done in this area. Given that satellite estimates will certainly remain the primary source of ground cover data for modelling purposes, developing a new conversion function with this understanding should be a priority. Further research is required and suggested for determining a more appropriate conversion function.

Keywords: $\quad$ Ground cover, remote sensing, water quality modelling, Great Barrier Reef 


\section{INTRODUCTION}

The Great Barrier Reef catchments have been the subject of considerable application of water quality models in recent times, due to high level of sediments and nutrients being delivered to the Reef. Results from this modelling have indicated that the hill slope erosion from grazing lands is the dominant source of sediment, as well as the dominant source of particulate phosphorus and nitrogen (Bartley et al, 2006). As ground cover is a dominant factor in hillslope erosion, accurate modelling is dependent on good quality estimates of ground cover.

Ground cover is temporally and spatially variable, as such remote sensing is an ideal source of cover estimates over large geographic areas. For the Reef, this information has historically been derived from the Bare Ground Index (BGI) or the related Ground Cover Index (GCI) (Scarth et al., 2006), which provide information on total ground cover at the Landsat scale once annually. Both these products were developed by the Queensland Department of Science, Information Technology, Innovation and the Arts (DSITIA)'s Remote Sensing Centre (RSC). Prior to the BGI/GCI, modellers were restricted to broad, temporally invariant estimates of ground cover at the sub-catchment scale (Searle and Ellis, 2009). As a consequence, the BGI/GCI has been readily adopted by the modelling community as a preferred source of ground cover information. The BGI/GCI has been utilised in numerous paddock scale (APSIM, GRASP and HowLeaky?) and catchment scale (SedNet, WaterCast and Source Catchments) water quality models for the Reef. The majority of these modelling frameworks rely on the RUSLE model for predicting hillslope erosion, which converts ground cover into the RUSLE C-factor (Searle and Ellis, 2009), typically using the conversion function defined by Rosewell (1993 and 1997).

While the modelling community has been largely favourable towards the BGI/GCI, there have been some limitations to its implementation. One major limitation at present is an apparent overestimation of ground cover predicted by the BGI/GCI, when compared with visual assessments. Bastin et al. (2008), found that the BGI/GCI appeared to overestimate ground cover, in comparison with visual assessment following the BOTANAL procedure, by $\sim 12 \%$ at two sites in the Charter's Towers region. Dougall et al. (2007) found that BGI/GCI overestimated ground cover, compared with visual ground measurements at several experimental sites, by approximately $30 \%$. If the GCI is over-predicting ground cover, this may result in considerable underestimates of erosion. However, it is not typically considered that BGI/GCI broadly overestimates ground cover given that the index is calibrated and validated against extensive field data ( $\sim 500$ sites). This ensures that on average estimates are unbiased. However in some areas there will be localised over- or underestimates of ground cover. As a result, satellite based estimates of ground cover, such as the BGI/GCI and the fractional cover Index (fCI), may not be suitable for small paddock scale modelling exercises without localised calibration.

A major difference between these satellite and field estimates of ground cover is that the field assessments were achieved using visual estimates of ground cover, whereas the satellite estimates were calibrated to point intercept data. Various authors have demonstrated that visual assessments of ground cover typically estimate less ground cover than point intercept/satellite estimates (Hatton et al., 1986, Murphy and Lodge, 2002, Abbot et al., 2008). This particularly occurs in the middle ranges of ground cover, with agreement at low levels and high levels of ground cover being greater, regardless of the measurement method (Murphy and Lodge, 2002, Abbot et al., 2008, Trevithick et al, 2012). In general point intercept methods are regarded as more reliable than visual estimates (ITT in Cagney et al., 2011; Booth et al., 2006). Booth et al. (2006) demonstrated that the point intercept method had the lowest coefficient of variation and highest correlation with known ground cover values. Given that the typical calculation of the C-factor is performed on ground cover data obtained from visual assessments, and given visual assessments are generally less than the point intercept methods on which the BGI/GCI is calibrated, it is reasonable to expect an underestimate of the RUSLE C-factor using satellite estimates.

The BGI/GCI has recently been replaced by a newer cover index, the fractional cover index (fCI). It is unknown what effect the fCI product will have on ground cover predictions in the Reef catchments, as well as the subsequent impact on erosion estimates. This paper introduces the fCI and compares the RUSLE Cfactor estimates for the Reef catchments calculated for both the BGI/GCI and fCI as well as explore the possibilities for correcting the conversion of ground cover to account for satellite estimates of ground cover rather than visual estimates of ground cover. 


\section{GROUND COVER INDEXES (BGI/GCI and fCI)}

Satellite estimates of ground cover in QLD have historically been produced as the Bare Ground Index (BGI) (Scarth et al. 2006), and the related Ground Cover Index (GCI). The GCI is simply 1 minus the BGI and so will be considered as the same product for the remainder of this paper (BGI/GCI). The BGI/GCI provides estimates of the levels of bare ground and total ground cover (green and non-green vegetation) at a pixel level ( $25 \mathrm{~m}$ ) from single date, dry-season Landsat imagery. Recently, however, the BGI/GCI has been replaced by the fCI (Scarth et al, 2010). Developed using spectral un-mixing methods, this product delivers more detailed information, separating total ground cover into green and dry vegetation fractions, provides more accurate information on ground cover than the BGI/GCI and provides some detail on the model performance at the pixel level.

The information used to derive the BGI/GCI product is based on the extensive archive of Landsat imagery held by the Remote Sensing Centre (RSC), dating back to 1986. However, due to limitations with obtaining imagery, the BGI/GCI was only produced once annually during the dry season. In comparison, the opening of the Landsat archive has resulted in the fCI product being produced at a temporal frequency not previously available for the GCI, and has resulted in the creation of a seasonal fCI product produced four times annually.

At present, neither the BGI/GCI nor fCI, can distinguish tree and mid-level woody foliage and branch cover from green and dry ground cover. As a result, in areas with even minimal tree cover $(>15 \%)$, estimates of ground cover become uncertain. To manage this, the BGI/GCI products are typically masked for areas of greater than $15 \%$ foliage Projective Cover (FPC) cover for the purposes of ground cover estimation. The increased temporal resolution available with the fCI is providing additional information about the dynamics and composition of vegetation cover over time. It has made possible the derivation of an estimate of 'persistent green' (Johansen, 2012), which provides an estimate of the vertically-projected green-vegetation fraction where vegetation is deemed to persist over time. These persistent areas are considered to be woody vegetation. The persistent green product is similar in nature to FPC product, also produced by RSC, with the exception that is derived directly from the underlying fCI product. This separation of the 'persistent green' from the fCI product, allows for the adjustment of the underlying spectral signature, which was not possible using the FPC product and as a result, is allowing for the extension of ground cover estimates into treed areas.

Both the BGI/GCI and the newer fCI are calibrated and validated against extensive field data. The current fractional model uses considerably more sites than the BGI/GCI for this purpose, due to having access to an additional 500 sites collected through an initiative by the Australian Bureau of Agricultural and Resource Sciences. Currently the fCI is calibrated against over 1000 sites from a range of environments across Australia, largely using a point intercept method, which has been adopted as the national standard for collection of ground cover data (Muir et al, 2011). The BGI/GCI was calibrated using site data from within Queensland only.

\section{METHOD}

For this analysis, the long term average bare ground products for the BGI/GCI and the fCI were used. The long term average was chosen to avoid any extreme results that may result from selecting a single given year or season. These two products report on the average dry season bare ground for each pixel, over the entire time-series of imagery available at RSC since 1986. The same dry season Landsat satellite images are used to create the products and both products are identically masked for cloud, cloud shadow and water. Each product was further masked for areas of FPC greater than 15\% using the 2006 and 2010 FPC products. Therefore the two ground cover products used are identical, with the exception that one was created using the $\mathrm{BGI} / \mathrm{GCI}$ and the other using the bare fraction of the fCI. Neither product can distinguish between dry detached cover and dry standing cover. There may be some scope to incorporate estimates of green cover as known standing cover in future work, however this is not within the scope of this paper.

Raster data for total ground cover were calculated as 1 minus the bare fraction for each of the long term timeseries rasters. The rasters were then clipped to catchment boundaries. Density distributions for each of the two ground cover rasters for each catchment were produced to highlight any differences in the ground cover distributions between the two indexes. The distributions for all catchments and both products were determined to be highly skewed towards high levels of ground cover. As such, the mean was not considered to be a suitable measure of central tendency; instead the median ground cover level was used.

For each of the ground cover rasters produced, the RUSLE C-factor was calculated for each pixel using the method outlined by Rosewell (1993 and 1997) for pastures. Using this method the C-factor is determined by an equation of the following form as described in Searle and Ellis (2009): 
Trevithick \& Scarth. Estimating RUSLE C-Factor Values for Great Barrier Reef Catchments using Satellite Derived Ground Cover Estimates

$$
C=e^{\left(-0.799-\left(4.74 \times 10^{-2} \times G C\right)+\left(4.49 \times 10^{-4} \times G C^{2}\right)-\left(5.2 \times 10^{-6} \times G C^{3}\right)\right)}
$$

Where GC is total ground cover as a percentage (\%).

Difference rasters for both the C-factors and total ground cover were then calculated by subtracting the $\mathrm{BGI} / \mathrm{GCI}$ layers from the fCI layers. This was done to establish if the C-Factor and total ground cover were increasing or decreasing, at the pixel scale, with the introduction of the new fCI index. Density distributions and medians were again calculated, this time for the ground cover and $\mathrm{C}$-factor differences for each catchment.

Satellite ground cover estimates were adjusted to the equivalent visual estimate by fitting a curve to the average of two equations described in two studies: Murphy and Lodge (2002) and Abbott et al. (2008). Both these studies report similar relationships between visual and satellite or point intercept estimates of ground cover respectively. The term 'objective' is used here to encompass both of these methods. Given the fCI is calibrated against point intercept data, this is considered a reasonable assumption. The equation used was:

$$
\text { Visual }=0.925 \times \text { Objective }^{2}
$$

where all measurements are given as fractions. The adjusted visual estimates were then converted into a percentage and the C-Factor calculated. This leads to an almost linear relationship between objective ground cover and the RUSLE C-factor (Figure 1). The distributions and medians for these adjusted C-

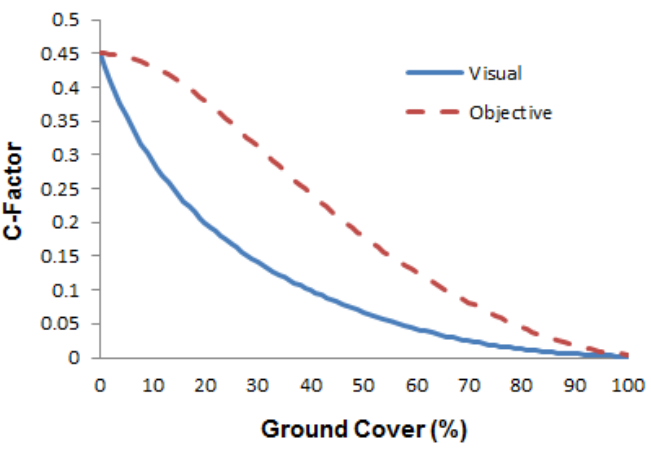

Figure 1. Standard Rosewell C-factor curve (based on visual quadrat ground cover estimates) and adjusted Rosewell curve for satellite derived ground cover estimates (based on objective laser point intercept estimates) factors were also calculated.

\section{RESULTS}

The density distribution graphs for each of the Reef catchments showed a consistent variation in the distribution of ground cover between the two ground cover indexes. As an example, the density distribution for the Fitzroy catchment is displayed in Figure 2, however all the catchments display a similar pattern. Typically, the ground cover distribution becomes slightly less skewed for the fCI than the BGI/GCI and the heavy tail of the BGI/GCI, at low levels of ground cover, is considerably reduced

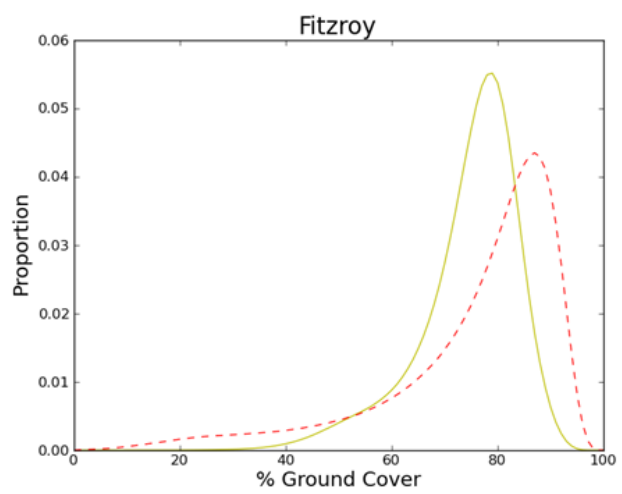

Figure 2. Ground cover density distributions for the BGI/GCI derived ground cover (red dashed line) and the fCI ground cover (yellow solid line) for the Fitzroy Catchment. 
Trevithick \& Scarth. Estimating RUSLE C-Factor Values for Great Barrier Reef Catchments using Satellite Derived Ground Cover Estimates

The medians derived from the ground cover difference density distributions indicate that for the majority of catchments, including the larger inland ones, the median ground cover levels have typically reduced, or at least remained the same (Figure 3a). However, the median C-factors for all the catchments have either not changed or decreased (Figure 3b). This is attributed to the reduction in the heavy tail of the BGI/GCI distribution compared with the fCI distributions and the heavy skew of the distributions for both products to higher levels of ground cover in the reef region. The Rosewell C-factor conversion function is an exponential function, where small changes in high levels of cover result in inconsequential changes in the $\mathrm{C}$-factor. The catchments whose median $\mathrm{C}$-factors decreased are those in which the fCI median cover was substantially higher than the BGI/GCI.

The adjustment to account for the satellite source of ground cover data, rather than visual estimates, has resulted in a considerable impact on resulting $\mathrm{C}$-factors. The distribution of the $\mathrm{C}$ factors for the BGI/GCI and the fCI where largely identical, dominated by low values with a steep decline and low median values for all catchments and both indexes. For example, the median C-factors for the two largest inland catchments, the Fitzroy and the Burdekin, remained unchanged between the two indexes at 0.01 . Both distributions were heavily dominated by low $\mathrm{C}$-factors. In comparison, the $\mathrm{C}$-factor for the corrected fCI distribution is considerably different, approximating a skewed normal distribution. The median values for the adjusted $\mathrm{C}$-factors for the Fitzroy and Burdekin are 0.05 and 0.06 respectively. The $\mathrm{C}$-factor distribution curves for the Fitzroy catchment for all indexes is displayed in Figure 4.

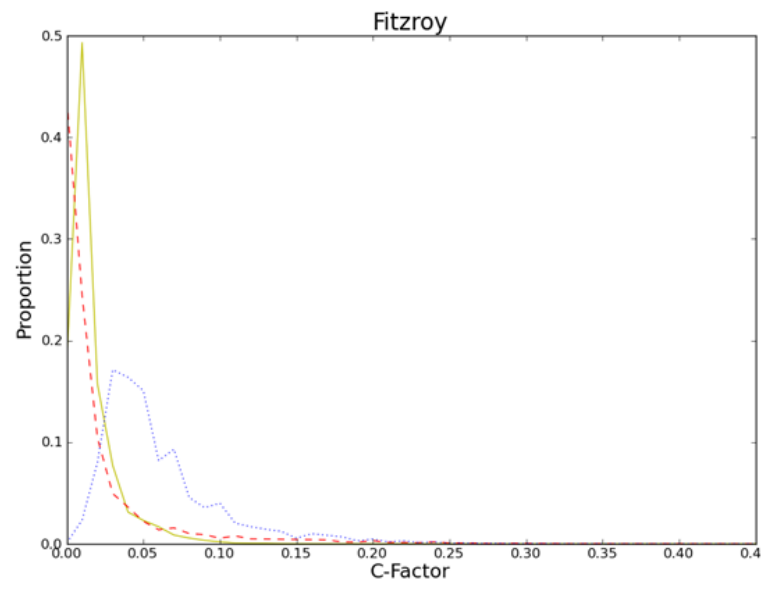

Figure 4. C-factor distributions for each ground cover index. (BGI/GCI - red dashed line, fCI - yellow solid line, adjusted-fCI - blue dotted line). a)
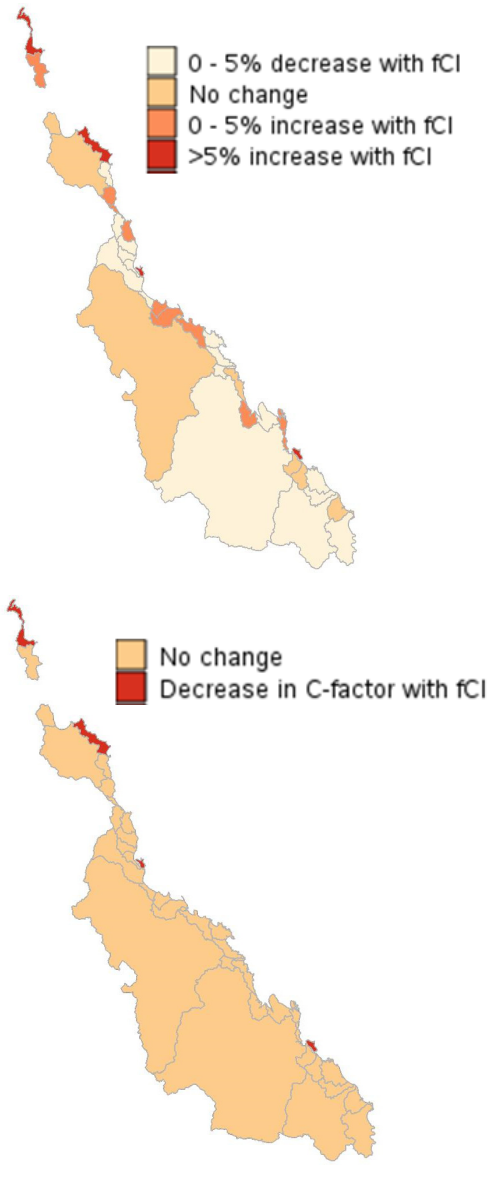

Figure 3a. Median ground cover differences between the BGI/GCI and the fCI for Great Barrier Reef Catchments. Figure 3b. Median C-factor differences between the BGI/GCI and fCI for the Great Barrier Reef Catchments.

Although the median C-factors between the two uncorrected indexes for the major inland catchments have not changed, there are spatial variations within the catchments and localised areas where there are considerable drops in C-factor values with the fCI. If these areas are otherwise highly vulnerable to erosion, then a large drop in the $\mathrm{C}$-factor could potentially be important as it would reduce erosion estimates at these locations. Figure 5a shows the spatial distribution of the C-factor differences for the BGI/GCI and fCI in the Burdekin and Fitzroy catchments. The green areas indicate a notable drop in the C-factor. In comparison, the spatial distribution of the difference between the BGI/GCI and the adjusted-fCI C-factors (Figure $5 \mathrm{~b}$ ) shows considerable areas of very high increases in the $\mathrm{C}$-factor. These areas are those with lower starting ground cover 
Trevithick \& Scarth. Estimating RUSLE C-Factor Values for Great Barrier Reef Catchments using Satellite Derived Ground Cover Estimates

levels, as the adjustment has the greatest effect in the mid-ranges of ground cover. The effect of the adjustment shown here in the Fitzroy was to reduce median ground cover from $75 \%$ (BGI/GCI) to $52 \%$ (adjusted-fCI).

\section{DISCUSSION AND CONCLUSIONS}

There will be very little predicted difference in hill-slope modelling erosion predictions with the introduction of the new fCI product into Reef catchment models. While the density distributions of ground cover throughout these catchments have altered, with a slight reduction in median ground cover values, this does not translate into any appreciable difference in the RUSLE C-factor (with the exception that in some small areas an actual reduction in the $\mathrm{C}$-factor will occur). The lack of change in the $\mathrm{C}$-factor is attributed to the high levels of ground cover predicted for both the BGI/GCI and fCI in the Reef catchments. Slight changes in predicted ground cover at high levels, have minimal effect with the current conversion function used.

While the adoption of the fCI for modelling purposes will in itself make very little difference to predictions, the adjustment of the ground cover estimates to account for the use of satellite imagery (adjusted-fCI) over visual estimates would have a considerable effect. The median ground cover values for the Fitzroy and Burdekin alone would reduce by 20 percentage points and the $\mathrm{C}$-factor values would experience a greater than 5 fold increase between the BGI/GCI and adjusted-fCI. Similar increases would occur in the smaller catchments. There would also be variation in the spatial distribution of these increases, which in itself would affect modelling outcomes.

When compared to the suggested figures for C-factors proposed by Rosewell (1993), the range of C-factor values for the both the BGI/GCI and fCI indexes, as well as the corrected fCI index, are all reasonable estimates for rangelands, depending on level of ground cover and plant community (Rosewell, 1993). There is unfortunately a lack of on-ground erosion data at an appropriate scale to assess the validity of any $\mathrm{C}$-factor estimates from satellite data. While the conversion function between satellite and visual estimates presented here is sound theoretically, it relies on an accurate determination of the relationship between visual and objective estimates and there is limited research done in this area. Given the considerable impact of the adjustment of ground cover in this manner on the $\mathrm{C}$-factor, it should be incorporated into erosion calculations cautiously.

The fCI offers many new opportunities to improve estimates of hillslope erosion, including the development of seasonal cover and estimates of ground cover under trees. However, any estimates of $\mathrm{C}$-factors using these products should consider that the current $\mathrm{C}$-factor conversion function was developed based on plot based visual assessments of ground cover and not satellite estimates. Given that satellite estimates will certainly remain the primary source of ground cover data for modelling purposes for the GBR catchments, developing a new conversion function with this understanding should be a priority. So, while it is hoped the information presented here will assist modellers determine the appropriate correction for specific applications, it is merely a first attempt at adjusting $\mathrm{C}$ -

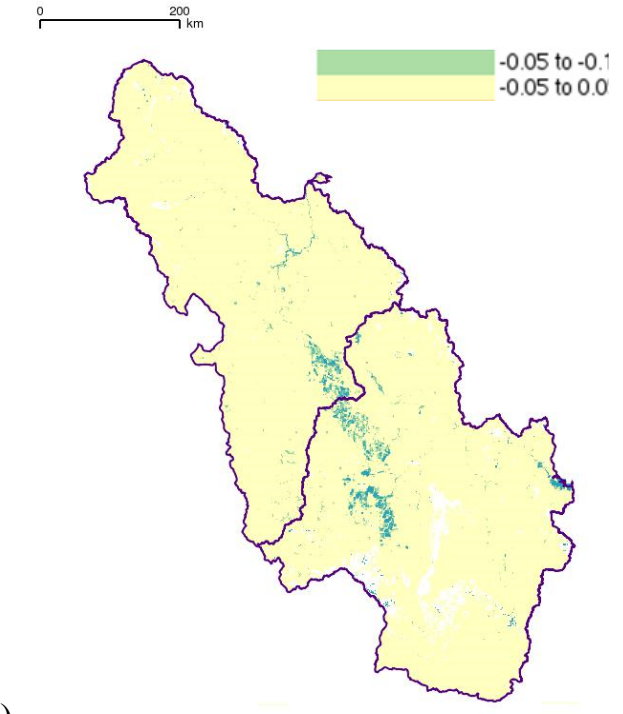

a)

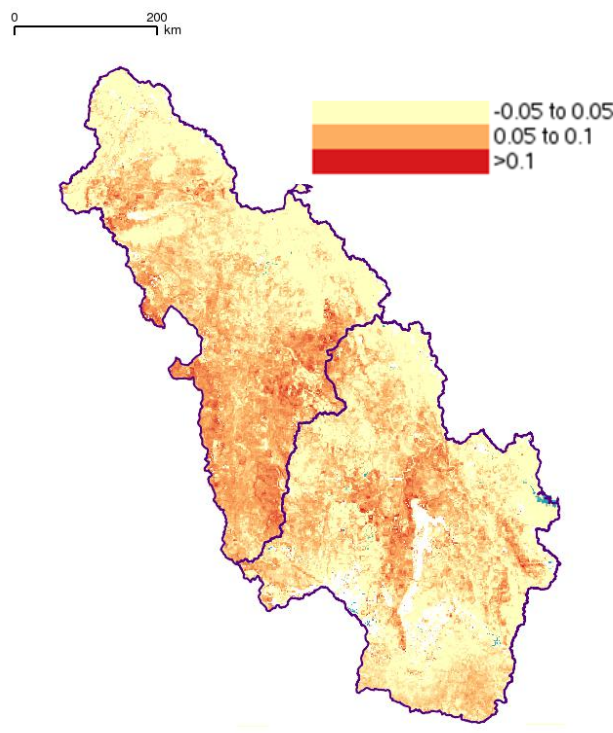

b)

Figure 5. C-factor difference images for the Fitzroy and Burdekin Catchments $(\mathrm{a}-\mathrm{fCI}, \mathrm{b})$ adjusted-fCI). White areas indicate no data due to foliage cover. The two legends represent $\mathrm{C}$-factor changes and are applicable to both maps. 
Trevithick \& Scarth. Estimating RUSLE C-Factor Values for Great Barrier Reef Catchments using Satellite Derived Ground Cover Estimates

factor conversions to account for the source of ground cover data. Further research is required and suggested for determining a more appropriate conversion function.

\section{REFERENCES}

Abbott, B., Perry, J. and Wallace, J. (2008). Land Condition Monitoring in the Rangelands of the Burdekin Dry Tropics Region. Task 4 - Prioritisation of D - Condition Land for Rehabilitation Report for the Burdekin Dry Tropics Board.

Bartley, R., Roth, C. H., Ludwig, J., McJannet, D., Liedloff, A., Corfield, J., Hawdon, A. and Abbott, B. (2006). Runoff and erosion from Australia's tropical semi-arid rangelands: influence of ground cover for differing space and time scales. Hydrol. Process., 20: 3317-3333. doi: 10.1002/hyp.6334

Bastin, G., Abbott,B. and Chewings, V. (2008). Validating a Remotely Sensed Index of Landscape Leakiness in the Burdekin Dry Tropics, Queensland. Report for the Reef Catchment Systems Project Water for a Healthy Country Flagship (Healthy Water Ecosystems Theme).

Booth, D.T., Cox, S.E., Meikle, T.W., \& Fitzgerald, C. (2006). The Accuracy of Ground-Cover Measurements. Rangeland Ecology \& Management, 59, pp. 179-188.

Cagney, J., Cox, S.E. and Booth, D.T. (2011). Comparison of Point Intercept and Image Analysis for Monitoring Rangeland Transects. Rangeland Ecology \& Management. 64(3), pp. 309-315.

Dougall, C., Carroll, C., Herring, M. and Trevithick, R. (2007) Sednet Modelling in the Fitzroy Basin (2007); Spatially Variable Ground Cover and Revised Gully Layers Can Potentially Generate Significant Changes in Erosion Sources and Patterns. Modsim07.

Hatton, T.J., West, N.E. and Johnson, P.S. (1986). Relationships of the error associated with ocular estimation and actual total cover. J. Range Manage. 39: 91-2.

Johansen, K., Gill, T., Scarth, P. and Phinn, S.R. (2012). Landsat based Time-Series of Perennial Foliage Projective Cover of Australia, In: Proceedings of the XXII Congress of the International Photogrammetry and Remote Sensing Society 2012, Melbourne, Australia, 25 Aug - 1 Sept 2012.

Muir, J., Schmidt, M., Tindall, D., Trevithick, R., Scarth, P., and Stewart, J.B., 2011, Field measurement of fractional ground cover: a technical handbook supporting ground cover monitoring for Australia, prepared by Queensland Department of Science, IT, Innovation and the Arts for the Australian Bureau of Agricultural and Resource Economics and Sciences, November.

Murphy, S.R. \& Lodge, G.M. (2002). Ground cover in temperate native perennial grass pastures. I. A comparison of four estimation methods. Rangeland Journal, 24(2), pp. 288-300.

Rosewell CJ (1993) 'SOILOSS - a program to assist in the selection of management practices to reduce erosion.' Technical Handbook No. 11, 2nd edn (Soil Conservation Service of New South Wales: Sydney)

Rosewell C.J. (1997). Potential Sources of Sediments and Nutrients:Sheet and Rill Erosion and Phosphorus Sources. Australia: State of the Environment Technical Paper Series (Inland Waters). Environment Australia, part of the Department of the Environment, Sport and Territories Commonwealth of Australia 1997

Scarth, P., Byrne, M., Danaher, T., Henry, B., Hassett, R., Carter, J., and Timmers, P. (2006). 'State of the paddock: monitoring condition and trend in groundcover across Queensland', in Proceedings of the 13th Australasian Remote Sensing and Photogrammetry Conference, Canberra, Australia, November 2006.

Scarth P, Roeder A and Schmidt M (2010). Tracking grazing pressure and climate interaction - the role of Landsat fractional cover in time series analysis. In '15th Australian Remote Sensing and Photogrammetry Conference'. Alice Springs. (Eds Sparrow, B and Bhalia, G).

Searle, R. D. \& Ellis, R.J. (2009). Incorporating variable cover in erosion algorithms for grazing lands within catchment scale water quality models. 18th World IMACS / MODSIM Congress, Cairns, Australia 13-17 July 2009

Trevithick, R., Muir, J. and Denham R. (2012). The effect of observer experience levels on the variability of fractional ground cover reference data. In: Proceedings of the XXII Congress of the International Photogrammetry and Remote Sensing Society 2012, Melbourne, Australia, 25 Aug - 1 Sept 2012. 